Classification

Physics Abstracts

$61.16 \mathrm{D}-68.35 \mathrm{~F}$

\title{
TEM investigation of iron segregation modes in CuAlFe dilute alloys
}

\author{
A. Hauet, A. Bigot and D. Blavette \\ Faculté des Sciences de Rouen, URA 808, 76821 Mont Saint Aignan Cedex, France
}

(Received June 3; accepted October 7, 1994)

\begin{abstract}
Résumé. - La solubilité du fer dans le cuivre est très faible (quelques $\%$ à $1000^{\circ} \mathrm{C}$ ), et on sait qu'elle demeure faible dans la solution solide $\alpha$ de cuivre aluminium. Nous décrivons ici les modes de ségrégation du fer observés au cours du refroidissement lent des solutions solides $\alpha$ (CFC) et $\beta$ (CC) d'alliages ternaires $\mathrm{CuAlFe}$ de teneurs en $\mathrm{Al}$ proches de $10 \%$ mass. et contenant $4 \% \mathrm{Fe}$. A haute température, le fer a d'abord tendance à ségréger en fer $\alpha$ ou en fer $\Gamma$; lorsque la température diminue, on observe la précipitation de phases riches en fer, mais contenant aussi du cuivre et de l'aluminium. Nous montrons en particulier que la phase stable $\alpha_{2}$ se forme trés vite, et nous pensons qu'elle est plus riche en fer que la matrice $\alpha$.
\end{abstract}

\begin{abstract}
Iron has a very low solubility in copper (a few $\%$ at $1000{ }^{\circ} \mathrm{C}$ ) as well as in the $\alpha$ solid solution of the $\mathrm{Cu}-\mathrm{Al}$ alloy. We describe here the iron segregation modes which are observed during the slow cooling of the $\alpha$ (FCC) and $\beta$ (BCC) solid solutions of $\mathrm{CuAlFe}$ alloys containing about $10 \mathrm{wt} \%$ $\mathrm{Al}$ and $4 \% \mathrm{Fe}$. At high temperature iron at first precipitates into $\alpha$ or $\Gamma \mathrm{Fe}$; then at lower temperature iron-rich phases are observed containing also $\mathrm{Cu}$ and $\mathrm{Al}$. Particularly, the $\alpha_{2}$ phase appears very quickly, and it is thought to be richer in Fe than the $\alpha$ matrix.
\end{abstract}

\section{Introduction.}

Iron is well-known for having a very low solubility in copper: from $3.8 \mathrm{wt} \%$ at $1094{ }^{\circ} \mathrm{C}$, it becomes almost negligeable at room temperature. Numerous studies of iron segregation in copper have been reported [1-3] and they have recently been extended to $\mathrm{Cu}-\mathrm{Al}-\mathrm{Fe}$ alloys containing up to 6 at. $\% \mathrm{Al}$, by Ishida and Kiritani $[4,5]$.

Our study deals with $\mathrm{Cu}-\mathrm{Al}-\mathrm{Fe}$ alloys with higher aluminium content. The Electron Microscope observation of alloys with compositions close to $\mathrm{Cu}_{3} \mathrm{Al}$ and containing a few \% $\mathrm{Fe}$, reveals the existence in the $\alpha$ phase of numerous coherent and incoherent precipitates which are different according to the $\mathrm{Al}$ content. At the same time the corresponding electron diffraction patterns show many diffuse lines characteristic of precipitation and ordering phenomena. In this paper, we intend to specify the different segregation modes of iron in these ternary alloys, by means of TEM and EDS analysis. This work follows fondamental studies dealing with order-disorder 
phenomena in binary and ternary $\mathrm{Cu}$ based alloys. Nevertheless it could also be of interest to pursue it on industrially used bronzes ( $\mathrm{Cu}-\mathrm{Al}-\mathrm{Ni}-\mathrm{Fe})$.

In the composition range studied, the $\mathrm{Cu}$ - $\mathrm{Al}$ phase diagram (Fig. 1) shows three high temperature equilibrium phases: the $\alpha$ FCC solid solution whose lattice parameter differs very slightly from that of copper, the disordered BCC $\beta$ phase, and the $\beta_{1}$ phase which is an ordered form of $\beta$ with a $\mathrm{DO}_{3}$ structure $\left(\mathrm{Fe}_{3} \mathrm{Al}\right)$.

By quenching $\beta$, the disordered $\beta^{\prime}$ and ordered $\beta_{1}^{\prime}$ martensites are obtained.

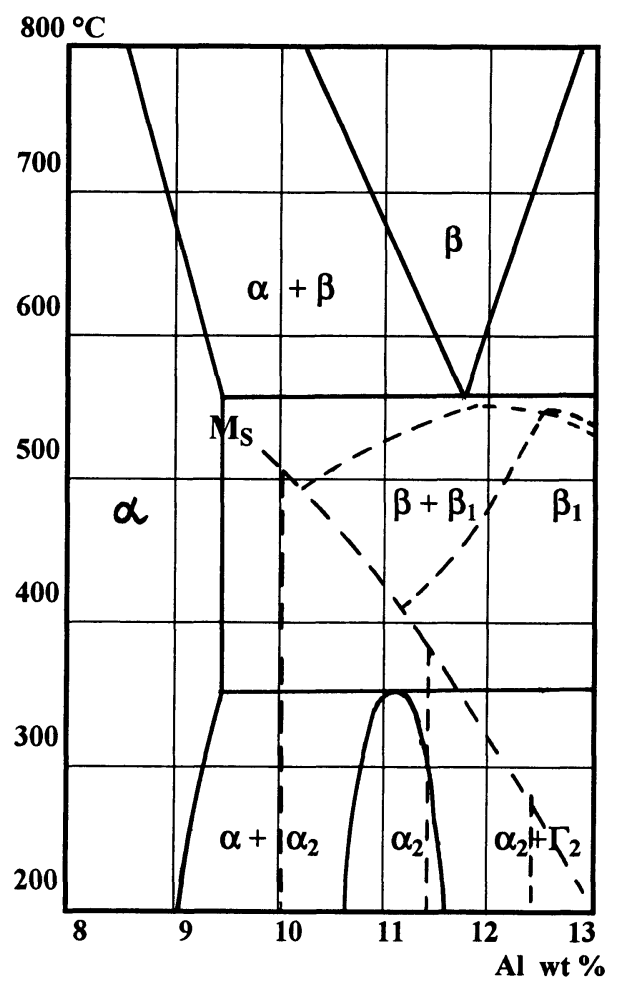

Fig. 1. - Phase diagram of $\mathrm{Cu}-\mathrm{Al}$ binary alloy.

Three equilibrium phases $\alpha, \alpha_{2}$ et $\Gamma_{2}$ coexist at low temperature. $\Gamma_{2}$, whose composition is close to $\mathrm{Cu}_{9} \mathrm{Al}_{4}$, has the cubic structure of $\Gamma$ brass. The structure of $\alpha_{2}$ was described by Duval [6]; the main feature of this ordered phase of $\mathrm{L}_{2}$ type is to exhibit periodic antiphase boundaries in the [001] direction.

On the diffraction patterns of $\mathrm{Cu}-\mathrm{Al}$ alloys containing 5 to $10 \mathrm{wt} \% \mathrm{Al}$ and cooled slowly $\left(5^{\circ} \mathrm{C} / \mathrm{h}\right)$ from $800^{\circ} \mathrm{C}$, Gaudig and Warlimont [7] observed diffuse spots which they ascribed to the precipitation of small $\alpha_{2}$ particles in the $\alpha$ phase.

Consıdering the faintness of this diffuse intensity, Scattergood, Moss and Bever [8] questioned this interpretation and assumed a short range order in $\alpha$.

In alloys cooled from $850^{\circ} \mathrm{C}$ at $15^{\circ} \mathrm{C} / \mathrm{h}$, Roland [9] obtained ordered domains of a phase with a basic reciprocal lattice plane very similar to that of $\alpha_{2}$, but which he supposed to result from a spinodal decomposition of $\alpha$. 
As for ternary $\mathrm{Cu}-\mathrm{Al}-\mathrm{Fe}$ alloys, they have been little studied. Le Maitre [10] pointed out that the phase diagram is very similar to the $\mathrm{Cu}-\mathrm{Al}$ diagram, except for the existence of globular iron-rich phases.

Moreover, a $\mathrm{BCC}$ phase containing $5 \% \mathrm{Cu}, 13.5 \% \mathrm{Al}$ and $81.5 \% \mathrm{Fe}$ of almost the same lattice parameter as iron and named $\delta$ is reported in the literature.

\section{Experimental.}

In order to study the segregation of iron in the $\alpha$ phase, four alloys with increasing $\mathrm{Al}$ contents (A,B,C,D) were synthesized (Tab. I). Materials were melted in an induction furnace and aged for 24 hours at $850^{\circ} \mathrm{C}$. Iron content was maintained nearly constant in all the specimens, about $4 \mathrm{wt} \%$, which corresponds to the solubility limit of iron in copper at $1094{ }^{\circ} \mathrm{C}$. The $\mathrm{Al}$ contents were chosen so that the high temperature equilibrium phases were $\alpha$ for A and B specimens and $\beta$ for $\mathrm{C}$ and $\mathrm{D}$. To check that, some samples $0,3 \mathrm{~mm}$ thick were quenched from $850^{\circ} \mathrm{C}$ in iced water and studied by TEM.

The four alloys were cooled to room temperature at the rate of $100{ }^{\circ} \mathrm{C} / \mathrm{h}$; the formation of the $\alpha$ phase requires the decomposition of the $\beta$ phase in the $\mathrm{C}$ and $\mathrm{D}$ specimens. Samples of thickness $0.1 \mathrm{~mm}$ were cut from the ingots and electrolytically thinned to be observed with an Electron Microscope JEOL 2000FX.

Table I. - Nominal composition of synthesized alloy (wt \%).

\begin{tabular}{|l|cccc|}
\cline { 2 - 5 } \multicolumn{1}{c|}{} & A & B & C & D \\
\hline Fe & 4.00 & 4.00 & 3.99 & 4.04 \\
$\mathrm{Cu}$ & 88.51 & 86.98 & 85.93 & 84.73 \\
$\mathrm{Al}$ & 7.50 & 9.01 & 10.07 & 11.20 \\
\hline
\end{tabular}

According to the compositions and heat treatments, the $\alpha$ solid solution ( $\alpha$ refers to the FCC phase of $\mathrm{Cu}-\mathrm{Al}$ alloy, ferrite will be called $\alpha$ iron) and the following phases were observed: the martensites, the $\Gamma_{2}$ phase of the binary system $\mathrm{Cu}-\mathrm{Al}$ and a very well crystallized iron-rich phase, which precipitates in large globules ranging from $500 \mathrm{~nm}$ to a few $\mu \mathrm{m}$ in diameter. We shall call it $\delta$, as its composition is very close to that of the $\delta$ phase mentioned in the literature.

E D S quantitative analysis uses the $\mathrm{K}$ lines of copper, aluminium and iron, the samples being set on a gold grid. In all our content measurements, the probe size (about ten $\mathrm{nm}$ in diameter), its brightness, the sample thickness (about $50 \mathrm{~nm}$ ) and the accelerating voltage $(200 \mathrm{Kv})$ allow a precision in the composition analysis of about $1 \%$. We verified also that, with the accuracy of our measurements, no noise could be detected in a hole count. However the measurement of light element contents, such as $\mathrm{Al}$, is delicate. As the iron content of the studied phases is often smaller than $1 \%$, precise values of compositions in $\mathrm{Fe}$ cannot be obtained; nevertheless the ranges of the iron content measured seem to show a significant evolution. 


\section{TEM observations.}

3.1 QUENCHED SAMPLES. - The samples B quenched from $900{ }^{\circ} \mathrm{C}$ are observed to be composed of very small martensitic areas, and of large crystals of $\alpha$ phase containing $\delta$ globules. The $\alpha$ phase is full of spherical coherent precipitates (Fig. 2a) revealed by their elastic strain contrast of Ashby Brown type, whith mean diameters smaller than $10 \mathrm{~nm}$. According to previous studies on $\mathrm{Cu}-\mathrm{Fe}$ [1-3], we are dealing with $\Gamma$ iron precipitates which segregated quickly during quenching. The average iron content measured in the $\alpha$ phase is $2.2 \%$. This value probably corresponds to the iron solubility in $\alpha$ at $900{ }^{\circ} \mathrm{C}$.
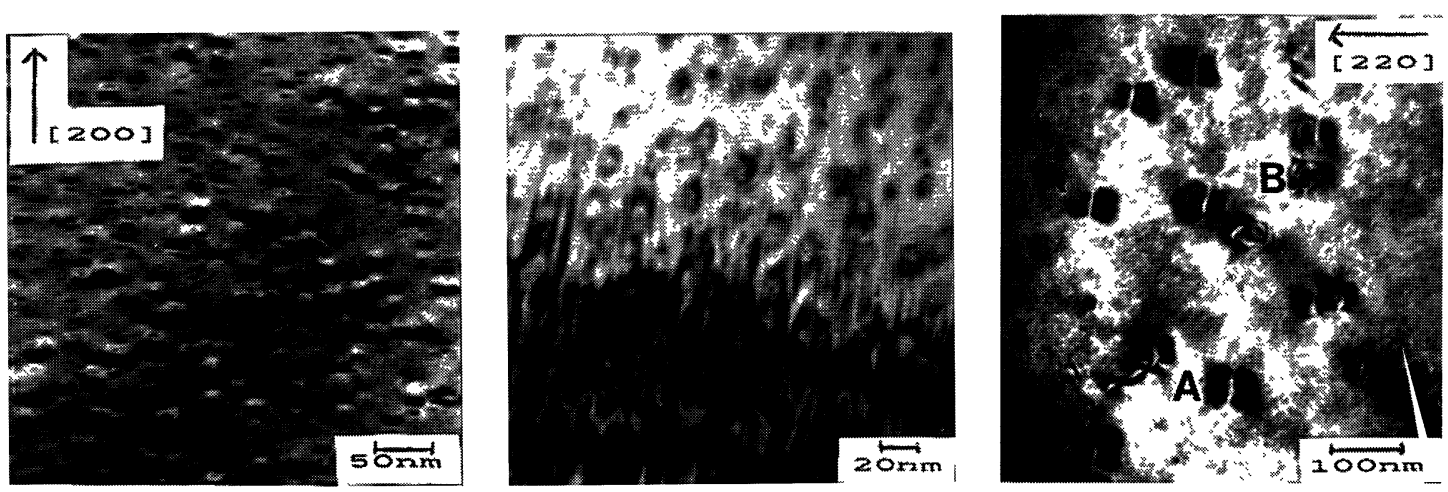

Fig. 2. - a) Precipitation of $\Gamma \mathrm{Fe}$ in quenched alloy B. b) Coherent precipitation in martensite in quenched alloy D. c) $\Gamma$ and $\alpha$ iron precipitates in slowly cooled A sample.

It can be concluded from these TEM observations that the sample $\mathrm{B}$, was close to the $\alpha / \alpha+\beta$ phase domain boundary at $900{ }^{\circ} \mathrm{C}$, since only small martensitic areas are detected. Thus the sample A containing less $\mathrm{Al}$ was probably in the $\alpha$ domain.

The samples $\mathrm{C}$ et $\mathrm{D}$ quenched from $850^{\circ} \mathrm{C}$ are found to be martensitic and present globules of $\delta$ phase. The martensite appears to contain less iron than the $\alpha$ phase (1.5 to 2.0\%) and it is probably the same for the $\beta$ phase from which it originates.

A very fine coherent precipitation can be observed in the martensite (Fig. 2b). It coexists with the $\beta_{1}^{\prime}$ precipitates which are visible only on dark field images. Probably, iron, initially in solution in the $\beta$ phase at $850^{\circ} \mathrm{C}$, segregated at first as $\alpha$ iron, whose lattice parameter does not differ significantly from that of the $\beta$ phase. These $\alpha$ iron precipitates then underwent the martensitic transformation with $\beta$ and $\beta_{1}$.

It can be concluded from these preliminary observations that, at $850^{\circ} \mathrm{C}, \mathrm{C}$ and $\mathrm{D}$ were in $\beta$ phase.

3.2 Slowly COOLED A AND B SAMPLeS. - The samples A are found to contain the $\alpha$ phase and $\delta$ phase intergranular and intragranular nuclei; this specimen can be compared to $\mathrm{Cu}-\mathrm{Fe}$ [1-3] and $\mathrm{Cu}-\mathrm{Al}-\mathrm{Fe}[4,5]$, but their microstructures are not identical. Three precipitation phenomena are distinguished in the $\alpha$ phase.

i) Small spherical precipitates under $50 \mathrm{~nm}$ in diameter. They are essentially coherent precipitates with average diameters above those observed in B quenched alloy. Around the largest, 
interfacial dislocations appear (semi-coherence); as some of them lose their coherence, the strainfield contrast changes and $\alpha$ iron diffraction spots are exhibited (Fig. 2c). This behaviour indicates that coherent precipitates contain mainly iron.

ii) Large precipitates 50 to $150 \mathrm{~nm}$ in diameter. Some of them contain small crystallites of a mixture of iron-rich phases; sometimes Moiré fringes are observed as a result of the overlapping of precipitates and matrix. Others present a banded structure, whose bands are perpendicular to the [110] matrix direction (Figs. 3a, b and c); such nuclei were interpreted in $\mathrm{Cu}-\mathrm{Fe}$ [1-3] as twinned $\alpha$ iron particles, the twin direction being [112] of $\alpha \mathrm{Fe}$, which is parallel to the [110] direction of the matrix. The orientation relationship of the FCC to the BCC structure is also the Pitsch relationship. The bands of twinned martensite are separated by non-transformed $\Gamma \mathrm{Fe}$ as in $\mathrm{Cu}-\mathrm{Fe}$ alloys, but a small quantity of the $\delta$ phase and of a $\mathrm{L}_{2}$ ordered phase is also identified. These precipitates contain 70 to $90 \mathrm{wt} \% \mathrm{Fe}$.

iii) In some areas, diffuse lines are evidenced by Electron Diffraction, mainly in the (100) planes of the $\alpha$ phase. More intense lines are found in B, C and D samples.More details will be given later. The weakly intense diffraction patterns of the (111) planes of a $\mathrm{L1}_{2}$ phase are also observed.
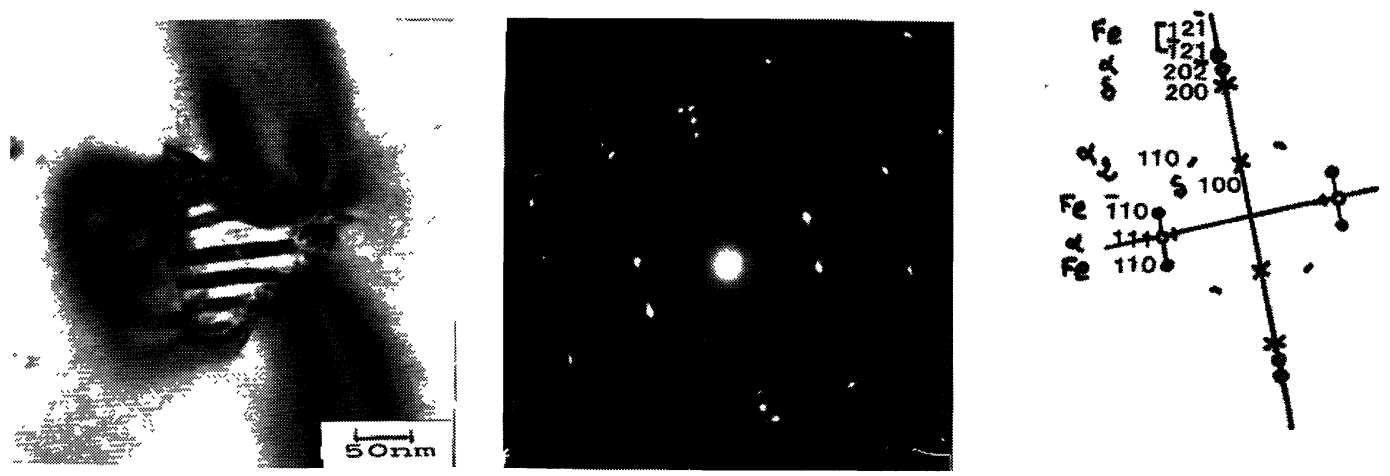

Fig. 3. - a) $\alpha$ iron with twins in sample A. b and c) Diffraction pattern corresponding to a).

Samples B differ slightly from samples A:

i) Large coherent precipitates $(d \sharp 50 \mathrm{~nm})$ are detected; they do not transform easily into $\alpha$ iron; this could be due to an enrichment in $\mathrm{Cu}$ and $\mathrm{Al}$.

ii) Although twinned banded precipitates are still formed, many large nuclei $(d>50 \mathrm{~nm})$ look different: cubic, smaller $(d<100 \mathrm{~nm})$, without bands and less rich in iron than those of A ( $\sharp 68 \mathrm{wt} \% \mathrm{Fe})$.

iii) Diffuse lines become more intense on diffraction patterns, especially in the (100) and (332) planes, the latter being obtained by a small rotation from a (111) plane around [220]. (Figs. 5a and b) Iron concentration in the $\alpha$ phase ranges from 0.60 to $0.80 \mathrm{wt} \%$ in A samples and 0.70 to $0.90 \%$ in $\mathrm{B}$ samples, larger than the equilibrium values.

3.3 SLOWLY COOLED C AND D SAMPLES. - These samples present martensitic areas, the globular $\delta$ phase, the $\Gamma_{2}$ phase of binary $\mathrm{Cu}-\mathrm{Al}$, forming mainly needle-like precipitates finely dispersed in $\alpha$ areas, characteristic of a perlitic eutectoid, and also large $\alpha$ phase crystals.

As far as our measurements could establish, iron seems be equally distributed in $\alpha$ and $\Gamma_{2}$ (Tab. II). 
Table II. - Fe and Al contents (wt \%) in $\alpha, \delta$ and $\Gamma_{2}$ phases of sample $D$ heat treated at $850^{\circ}$ and slowly cooled.

\begin{tabular}{|l|ccc|}
\cline { 2 - 5 } \multicolumn{1}{c|}{} & $\alpha$ & $\delta$ & $\Gamma_{2}$ \\
\hline A1 & 10.4 to 11.0 & 7.6 to 11.0 & 14.5 to 16.5 \\
Fe & 0.6 to 1.5 & 79.0 to 81.0 & 0.6 to 1.5 \\
\hline
\end{tabular}
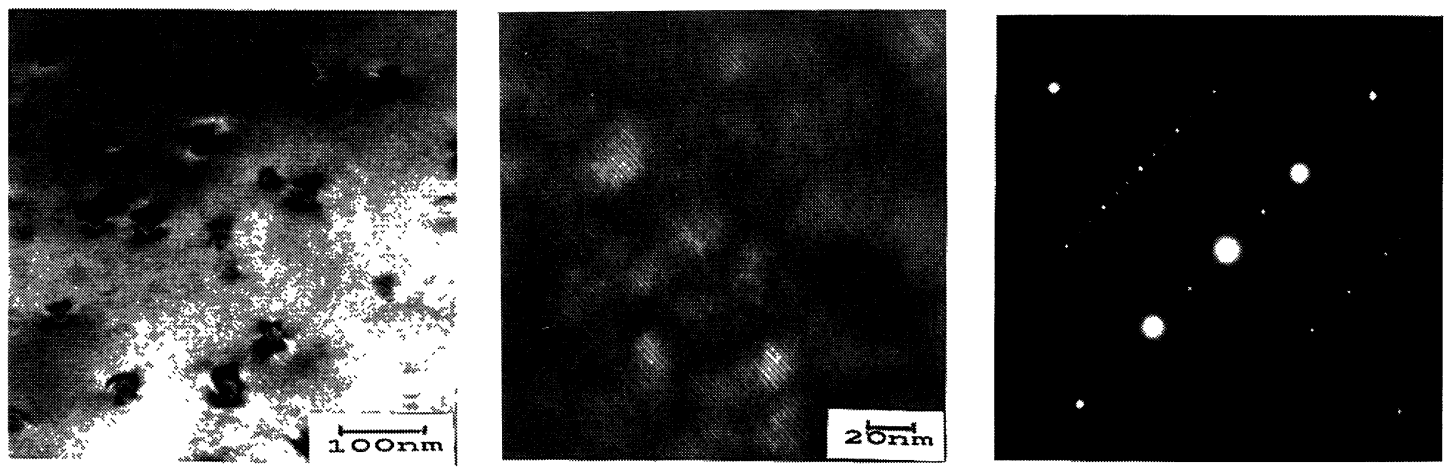

Fig. 4. - a) Iron-rich incoherent precipitates in sample C. b) Coherent precipitation of $\alpha_{2}$ in sample D. c) Diffraction corresponding to $b$ ).
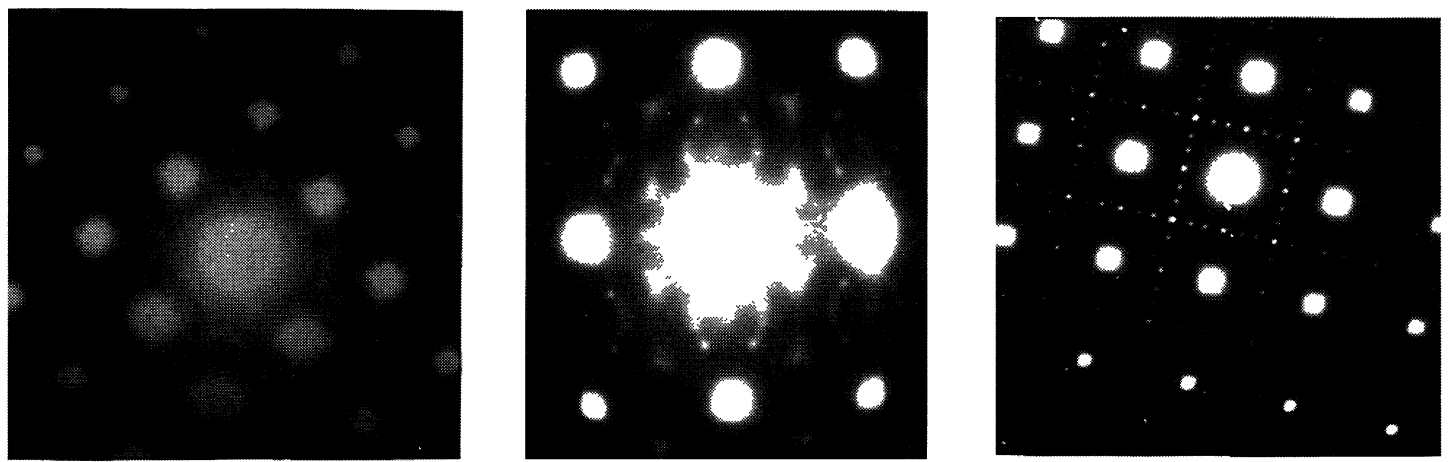

Fig. 5. - a) Diffuse lines and spots in (100) plane of $B$ reciprocal lattice. b) Diffuse lines and spots in (332) plane of B. c) (100) $\alpha_{2}$ diffraction pattern in D.

In the $\alpha$ phase two types of precipitation are evidenced by Electron Microscopy:

i) A precipitation of cubic particles under $100 \mathrm{~nm}$ in size, incoherent with the matrix, and often very small (10 to $20 \mathrm{~nm}$ ) (Fig. 4a). This precipitation is important in C, though it varies according to the area studied; it does not appear in sample D.

ii) A precipitation (visible only in dark field images) of separated nuclei larger in sample D 
than in sample C (Figs. 4b and c). It causes diffuse lines and superlattice spots in the $\alpha$ matrix, the latter being reinforced in $\mathrm{D}$ while the diffuse lines are weakened (Fig. 5c). As we are going to show, we have here an $\alpha_{2}$ phase.

The former precipitates i) are observed to be a mixture of phases: $\alpha$ iron and $\alpha_{2}$ phase.

\section{Discussion.}

4.1 THE $\delta$ PHASE. - We have tried to determine the composition and the structure of the ironrich $\delta$ phase. This precipitates in large globules (some $\mu \mathrm{m}$ in diameter) at grain boundaries, as well as inside the $\alpha$ phase and also in the martensites. Its lattice parameter is close to that of $\alpha$ iron. Different average iron contents are measured: $90 \mathrm{wt} \%$ in $\mathrm{A}$ and $\mathrm{B}$ and $81 \%$ in $\mathrm{C}$ and $\mathrm{D}$, while $\mathrm{Cu}$ and $\mathrm{Al}$ are present in the same proportions. This could be related to the size of the nuclei which are larger in $\mathrm{C}$ and $\mathrm{D}$ than in $\mathrm{A}$ and $\mathrm{B}$, and thus richer in $\mathrm{Al}$ and $\mathrm{Cu}$. Therefore at the same time, BCC partial order $(\mathrm{FeAl})$ is observed in samples $\mathrm{A}$ and $\mathrm{B}$, and $\mathrm{FCC}$ order $\left(\mathrm{Fe}_{3} \mathrm{Al}\right)$ is found in samples $\mathrm{C}$ and $\mathrm{D}$. Additional studies are necessary, which would allow the domain of existence of several $\delta$ type phases to be distinguished.

4.2 THE $\alpha_{2}$ PHASE. - In all the studied samples, a coherent precipitation is observed in the $\alpha$ phase; its reciprocal lattice shows diffuse lines or surfaces, and superlattice spots which are particularly intense in (100) and (332) planes. Our diffraction patterns can be compared to those observed by Miida [11] by Electron Diffraction on metal oxydes. For low Al content (A) very weak diffuse superlattice spots and streaks linking the spots appear. When the amount of $\mathrm{Al}$ is increased, these diffuse lines vanish and the superlattice spots become more intense.

The (100) planes look like the (100) plane of the $\mathrm{Cu}-\mathrm{Al} \alpha_{2}$ phase which was described [6] by introducing into the $\mathrm{L}_{2}$ lattice of $\mathrm{Cu}_{3} \mathrm{Al}$ two series of APB's in the [100] direction; the first one leads to the $\mathrm{DO}_{22}$ structure, and the second one, which occurs every four or five planes, produces the $\alpha_{2}$ structure, the period $N$ being 4 or 5 . The split spots appearing in the three equivalent [100] directions can be explained as originating from three families of $\alpha_{2}$ small precipitates (Fig. 5c).

The (332) plane patterns have never been described in $\mathrm{Cu}-\mathrm{Al}$, and then could originate from another ordered phase of the ternary alloy. It was verified by the EMS program realised by Stadlemann (Lausanne) that all the diffuse spots appearing on diffuse streaks or diffuse circular lines such as $(0,5 / 8,1)$ and $(0,1,11 / 8)$ belong to a $\alpha_{2}$ plane very near to $(3 \overline{3} 2)$. This is shown in figure 6 which is a $(3 \overline{3} 2)$ section of the reciprocal lattice and a projection on this plane of the antiphase doublets belonging to the neighbouring planes (16 $\overline{16} 11)$ and $(8 \overline{8} 5)$, in a $\alpha_{2}$ phase with $N=4$. We do not observe superlattice spots and diffuse lines on the (332) $\mathrm{Cu}$-Al plane, probably because of their low intensities, originating essentially from a larger value of the antiphases period, whose effect is to increase the distance between the antiphase split spots and the (332) plane.

We conclude that, in all the samples, microdomains of $\alpha_{2}$ phase containing APB's are formed during the cooling.

Evidently adding iron accelerates the $\alpha_{2}$ formation.

It is thought therefore, that $\alpha_{2}$ is richer in iron than the $\alpha$ phase. This could explain, i) why the iron concentration in the mixture $\alpha+\alpha_{2}(\mathrm{C}$ or $\mathrm{D})$ is significantly larger than in the $\alpha$ phase (A or B), ii) why we do not observe large iron-rich precipitates in $\mathrm{D}$, and iii) why the period of the antiphases differs from that observed in the binary alloy: 3.65 to 3.75 in C and D slow-cooled samples, which is smaller than the measured value in $\mathrm{Cu}-\mathrm{Al}$ [6]: 4 to 4.5 . By annealing sample $\mathrm{D}$ for $24 \mathrm{~h}$ at $320^{\circ} \mathrm{C}$, ordered domains become larger and the antiphase period only reaches 4 . 


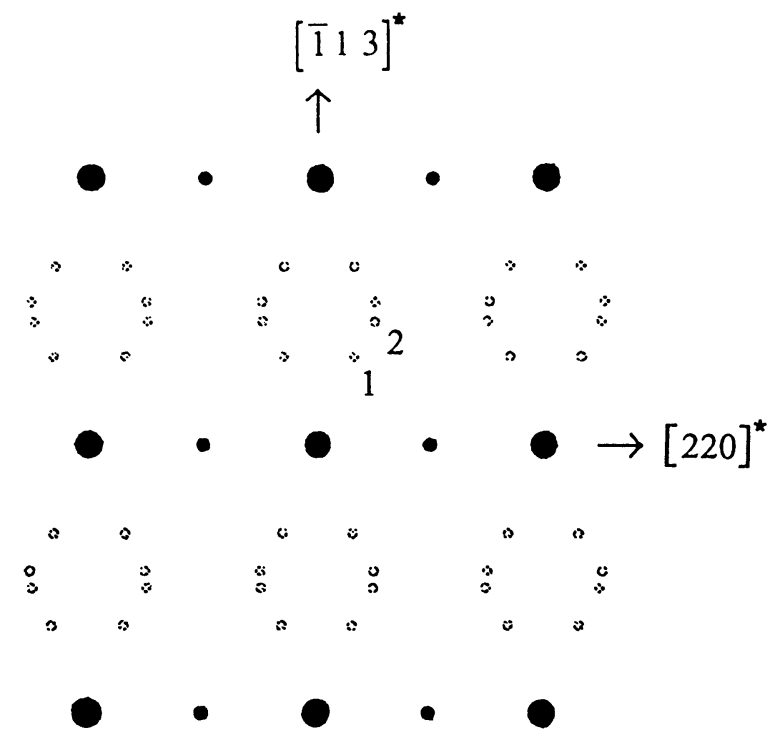

Fig. 6. - E.M.S. program simulation of $(3 \overline{3} 2)$ plane of the $\alpha_{2}$ phase $(N=4)$.

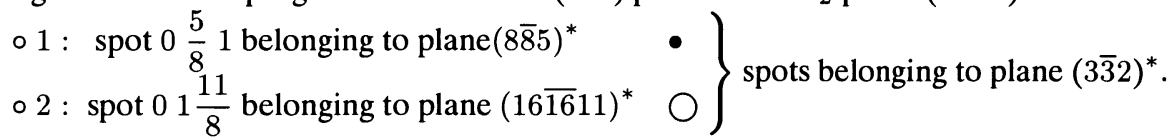

\subsection{SUCCESSIVE STEPS CONCERNING IRON SEGREGATION DURING COOLING OF Cu-Al-Fe ALLOYS} CAN BE SUMMARIZED AS FOLLOWS.

a) For the $\alpha$ phase supersaturated in iron:

- Precipitation of $\Gamma$ iron and rich-iron $\delta$ globules.

- Martensitic transformation of $\Gamma$ iron into $\alpha$ iron and coalescence of precipitates accompanied by an enrichment in $\mathrm{Al}$ and $\mathrm{Cu}$, followed by a partition between iron-rich phases and low iron content phases.

- Formation of a $\mathrm{L}_{2}$ ordered phase with APB's.

With increasing $\mathrm{Al}$ content we observe: an enrichment in $\mathrm{Al}$ and $\mathrm{Cu}$ of all the nuclei, which stops the martensitic transformation, and a faster formation of $\alpha_{2}$.

b) For the $\beta$ phase supersaturated in iron:

According to the chosen rate of cooling we observe first a competition between the two transformations: $\beta_{(1)} \rightarrow \beta_{(1)}^{\prime}$ and $\beta \rightarrow \alpha+\Gamma_{2}$, always accompanied by the $\delta$ phase formation.

Then a second transformation occurs:

$\alpha \rightarrow \alpha+\alpha_{2}+$ iron-rich precipitates for an $\mathrm{Al}$ content $<11.2 \%$

$\alpha \rightarrow \alpha+\alpha_{2}+$ for an $\mathrm{Al}$ content of $11.2 \%$.

Further investigations of the $\alpha_{2}$ phase in ternary $\mathrm{Cu}-\mathrm{Al}-\mathrm{Fe}$ alloys are currently being carried out in order to obtain additional information on this ordered phase. 


\section{References}

[1] Easterling K.E. and Miekk.oja H.M , Acta Met. 15 (1967) 1133.

[2] Kinsman K.R., Sprys J.W. and Asaro R.J., Acta Met. 23 (1975) 1431.

[3] Toshiyuki Fujii, T. Mori and Masaharu Kato, Acta Met. 40 (1992) 3413.

[4] Ishida I. and Kiritani M., Tr. Jap. Inst. Met. 27-8 (1986) 561.

[5] Ischida I. and Kiritani M., Acta Met. 36-8 (1988) 2129.

[6] Duval P., Thesis (1972), University of Rouen.

[7] Gaudig W. and Warlimont H., Act. Met. 26 (1978) 709.

[8] Scattergood R.O., Moss J.C. and Bever M.B., Acta Met. 18 (1970) 1087.

[9] Roland J.M., Quillard X. and Marya S.K., Phys. Stat. Sol. (a) 66 (1981) 347.

[10] Le Maitre F., Thesis (1970), University of Nantes.

[11] Miida R. and Tanaka M., Arashi H. and Ishigame M., J. app. Cryst. 27 (1994) 67. 